\title{
Different Styles for Different Needs - The Effect of Cognitive Styles on Idea Generation
}

\author{
Lomberg, Carina; Kollmann, Tobias; Stockmann, Christoph
}

Published in:

Creativity and Innovation Management

Link to article, DOI:

10.1111/caim. 12188

Publication date:

2017

Document Version

Publisher's PDF, also known as Version of record

Link back to DTU Orbit

Citation (APA):

Lomberg, C., Kollmann, T., \& Stockmann, C. (2017). Different Styles for Different Needs - The Effect of Cognitive Styles on Idea Generation. Creativity and Innovation Management, 26(1), 49-59.

https://doi.org/10.1111/caim.12188

\section{General rights}

Copyright and moral rights for the publications made accessible in the public portal are retained by the authors and/or other copyright owners and it is a condition of accessing publications that users recognise and abide by the legal requirements associated with these rights.

- Users may download and print one copy of any publication from the public portal for the purpose of private study or research.

- You may not further distribute the material or use it for any profit-making activity or commercial gain

- You may freely distribute the URL identifying the publication in the public portal

If you believe that this document breaches copyright please contact us providing details, and we will remove access to the work immediately and investigate your claim. 


\title{
Different Styles for Different Needs - The Effect of Cognitive Styles on Idea Generation
}

\author{
Carina Lomberg, Tobias Kollmann \\ and Christoph Stöckmann
}

\begin{abstract}
Researchers are engaged in finding the precursors for innovation. Drawing on Kirton's AdaptionInnovation (KAI) Inventory, we explicitly test Kirton's central premise that cognitive styles differentiate between preferences for producing ideas in a certain way. We argue that the generation of either a magnitude or original ideas is governed by different underlying cognitive styles. In a study with 191 individuals, we find that the cognitive style originality associates with ideational fluency whereas the rule governance style associates with the generation of original ideas. By providing a cognitive explanation for how ideas are generated, we deepen the understanding of the idea generation process. This is particularly important for the future use of the KAI and for organizations that strive to be innovative.
\end{abstract}

\section{Introduction}

T thas frequently been pointed out that today's Irapidly changing and highly competitive business environment accelerates the need for innovations among all organizations (e.g., Gino et al., 2010). In order to maintain and enhance their effectiveness and competitiveness, organizations strive to be innovative (Amabile, 2000; Paulus \& Nijstad, 2003; Davis, 2009). Individuals contribute to organizational innovation in the form of the generation of original and potentially valuable ideas concerning products, services and processes (Zhou \& George, 2001). Given the importance of ideas for innovation, the question how these ideas are generated should be solidly grounded.

Cognitive styles (e.g., Kirton, 1976) have been shown to be good predictors of creativity over and above personal attributes (e.g., Harrison et al., 2002). Hence, to add to a valid explanation of idea generation, we argue that cognitive processes underlying idea generation must be taken into account. Whereas research on idea generation has begun to address the cognitive processes underlying original idea generation (e.g., Nijstad, Stroebe \& Lodewijkx, 2003), little attention has been paid so far to the question whether the cognitive mechanisms underlying originality, i.e., the production of novel ideas, are different from those underlying fluency, i.e. the production of many ideas. Whereas originality seems to be necessary for breakthrough innovation (Taylor \& Greve, 2006), the ability to generate a large numbers of ideas (fluency) might be useful for innovations that are not built on a single discovery or invention such as considering several potential application markets (O'Connor \& McDermott, 2004). As both kinds of idea generation seem to be crucial for innovation, we shed light on the question whether a single person can complementary possess all cognitive skills required for ideational fluency and original ideas or whether the cognitive demands are rather contradictory. We base our analysis on a study with 191 individuals. Our results show that ideational fluency and originality of generated ideas indeed depend on the cognitive style of individuals.

Our research contributes to the creative style-creative level discussion, which has been debated for more than 40 years now, and contradicts Kirton's (1976) initial premise that cognitive styles are not related to creative outcomes. In doing so, we are among the first to explicitly test Kirton's (1976, 2003) central premise that cognitive styles differentiate between preferences for producing ideas in a certain way (and not the capability to act in a particular way when asked to do so). Drawing 
on recent findings by Miron-Spektor, Erez and Naveh (2011), we further advance the existing discussion around cognitive effects by not only examining fluency and originality effects based on an individual's positioning on the adaptioninnovation continuum within a given style, but explaining variance in these outcomes based on differences between (and not only within) styles. Our research contributes to the scholarly discussion around Kirton's AdaptionInnovation theory by offering an alternative way to explain why those individuals who attract attention by proliferating ideas may not be those who produce original ideas. In this regard, we also help organizations to assign creative tasks to the 'right' organizational members, and hence, offer guidance for an important stepping stone towards innovation in organizations: the generation of many and/or original ideas.

\section{Cognitive Styles and Creative Outcomes}

Cognitive styles are an individual's preferred way of gathering, processing and evaluating information (Hayes \& Allinson, 1994; Puccio \& Grivas, 2009). Thereby, cognitive styles influence the way individuals perceive their environment in order to search for information, to make sense of it and to store it within their mental models to make use of it for further actions. Cognitive styles have been found to be at the core of creative achievements (e.g., Kirton, 1976; Tierney, Farmer, \& Graen, 1999).

One approach to understanding and measuring cognitive styles that has received considerable attention in the literature is based on Kirton's Adaption-Innovation theory (1976, 1994, 2003). Kirton (2003) posits that people solve problems and develop solutions in different ways. People can be placed on a bipolar continuum ranging from adaption to innovation on three cognitive styles: originality, efficiency and rule governance. The first - originality - is similar to Roger's (1959) concept of the 'creative loner' who compulsively toys with ideas. Innovators in this style do not bother about paradigm structures but do proliferate ideas, whereas adopters in this style operate within the prevailing paradigm and prefer to produce fewer but sound, useful and relevant ideas (Kirton, 2003). The second - efficiency - is similar to Weber (1970) when describing bureaucrats. Innovators in this style prefer to loosen structure and shed detail, whereas adaptors are concerned with precision, reliability and attention to detail (Kirton, 1994). The third rule governance - resembles Merton (1957) in his analysis of managers. The Mertonian conformist, i.e. the adaptor, fits well into organizational settings as he has proper respect for authority and rules, whereas the innovator is a rule-breaker, who challenges or at least disregards existing rules and structures (Kirton, 2003). Although Kirton (e.g., 1987, 2003; see also Kaufmann, 2004) asserts that his measures capture creative styles (i.e., preferences), and not creative levels (i.e., creative capability), the literature has continuously found innovation as compared to adaption in the styles associated with creative outcomes (e.g., Isaksen \& Puccio, 1988; Miron-Spektor et al., 2011).

Although some research has aggregated these three cognitive styles into one continuum with two poles (e.g., Kirton, 1976), the broad majority of research confirmed a three-factor structure, with inconsistent correlations between the styles, and each style exerting different associations with outcome variables (e.g., Isaksen \& Puccio, 1988; Taylor, 1989b; Bagozzi \& Foxall, 1995), suggesting that three different styles exist (Miron, Erez \& Naveh, 2004). While, in principle, people can score high on measures of more than one style, people tend to have a strong preference for one style over the others (Miron-Spektor et al., 2011). Whereas traditional research on cognitive styles has extensively examined the outcome effects based on an individual's positioning on the adaption-innovation continuum within a given style, the finding by Miron-Spektor and colleagues (2011) encourages researchers to direct more attention to the effects of a high preference for a certain style, i.e. explaining outcomes based on differences between (and not only within) styles. Miron-Spektor et al. (2011) assume that only the originality style is associated with idea generation, whereas the efficiency and rule governance styles are associated mainly with idea implementation. This assumption partly accords with more traditional findings. For example, Lowe and Taylor (1986) show that the originality style is strongly associated with creative performance, whereas the efficiency style is associated with skills performance, i.e. assiduous, penetrating, and skilful work in the testing of ideas, rather than with creative performance. Miron and colleagues (2004) found a positive correlation between attention-to-detail, which is similar to efficiency, with performance quality but not with innovation. Likewise, Isaksen and Puccio (1988) do not find a significant correlation between efficiency and any Torrance creativity measure. However, as Miron-Spektor and colleagues (2011, p. 742) note, '[c]onformists' effects on idea generation are less clear, because research findings have been inconsistent'.

Two shortcomings in the literature might be the reason for these inconsistent findings that 
concern not only the contribution of rule governance to idea generation. The first (analytical) shortcoming is the almost exclusive analysis of zero-order correlations (e.g., Isaksen \& Puccio, 1988), which does not account for the confounding correlation between the styles, resulting in a biased estimate of the correlation between any of the styles with an outcome variable. These correlational findings on the cognitive style-creative performance stem primarily from early research. Yet, although we have made substantial methodological advances to date, this early research is still often cited and used for building hypotheses and supporting results (e.g., Kirton, 2003; Miron-Spektor et al., 2011). Not controlling for correlations between the styles, may have led to erroneously finding comparable contributions of the different cognitive styles on outcome variables.

The second (thematic and methodological) shortcoming is the ignorance of one of Kirton's central premises. Kirton premises in his A-I theory that differences in cognitive styles explain how individuals prefer to produce ideas. Hence, if individuals are not explicitly asked to act in a particular way, they will generate ideas in their preferred ways. However, if asked to do so, individuals may also be able to, for example, generate a large number of ideas, irrespective of their preferred cognitive style (Kirton, 2003). This is important because some prior studies have used different tests to capture creative outcomes, such as fluency and originality (c.f. Isaksen and Puccio, 1988). Given that different tests have different stimuli and the stimulus at hand may influence participants' response behaviour (Kim, 2006), clear differences in creative outcomes as a function of a certain cognitive style may be masked. For example, a certain stimulus might be interpreted as asking for many rather than innovative responses. According to Kirton (2003), this may cause more or less favourable results in any of these tests, irrespective of their preferred cognitive style. Omitting this premise may lead to a distortion of the results when aiming at finding different effects of the cognitive styles on certain outcome variables, as in the context of our study.

\section{Hypotheses}

We propose that the cognitive styles 'originality' and 'rule governance' contribute to idea generation, whereas - as discussed in the previous section and in line with existing research (e.g., Lowe \& Taylor, 1986; Isaksen \& Puccio, 1988; Miron et al., 2004; Miron-Spektor et al., 2011) - we do not assume an effect of the cognitive style efficiency on any of the outcome variables. Although we assume that both originality and rule governance contribute to idea generation, we argue that the styles differ in the kind of idea generation, fluency and originality they affect. In the following, we present rationales linking the creative styles 'originality' and 'rule governance' to fluency and originality in idea generation.

The first creative style - originality - differentiates between sufficiency of originality on the one hand and proliferation of originality on the other (Kirton, 1994). Kirton's (2003) basic descriptions of the two extremes start by stating that people tending to sufficiency of originality prefer to produce fewer ideas which are aimed to be seen as sound and useful. In contrast, people tending to proliferation of originality prefer to proliferate ideas with low regard for the prevailing structures and with accepting that much of their idea output may be discarded as long as one or two pay off. Therefore, it can be assumed that proliferation of originality is associated with a high fluency in idea generation. Isaksen and Puccio (1988) report a positive and significant relationship between the creative style originality and verbal fluency. Thereby, they provide empirical support for this relationship. Arguing that team members possessing originality provide their teams with a large pool of ideas from which to choose, Miron-Spektor and colleagues (2011) find a positive effect of the proportion of such members on a team for radical innovation. Discussing his own results and prior research by Payne (1987), Taylor (1989b, p. 305) concludes that the originality scale 'must be correlated with the capacity to generate ideas', regardless of quality. Proliferators of ideas are less concerned, and may not even notice the boundaries associated with a particular paradigm. Accordingly, this results in generating both paradigm-consistent and paradigm-cracking ideas (Kirton, 2003). Some of the many ideas they produce appear more adaptive, others more innovative (Kirton, 1999). Taylor (1989b) recognizes that, with respect to the originality style, A-I theory says nothing about the quality of the ideas generated, and that the production of an abundance of low quality ideas would accord with the proliferator type. This facet of the proliferation of originality type indicates why a clear effect of this cognitive style on generating original ideas cannot be expected.

\section{Hypothesis 1. Proliferation of originality is positively associated with ideational fluency.}

The cognitive style 'rule governance' differentiates between rule-conforming and rulebreaking managing structures (Kirton, 2003). In this context, rule governance covers operating within policies, theories, conventions and 
consensus. Such a context has traditionally been seen as contradictory of creativity, which requires thinking outside the box (Miron-Spektor et al., 2011). High levels of such conformity may restrict the generation of original ideas, as it suppresses deviations from acceptable norms and standards (Goncalo \& Staw, 2006). It also restricts the expression of original, deviant ideas, as rule-conformers fear receiving negative evaluations of their social or occupational groups (Diehl \& Stroebe, 1987). People with a rule-breaking tendency, however, are less responsive to pressures to conform and are willing to provoke challenging and unexpected changes (Kirton, 2003). While conformers are concerned about cohesion, rule-breakers are willing to solve problems and develop ideas at the expense of rule and group cohesion (Kirton, 2003). Especially for radical innovation, individuals need to raise ideas that are nonstandard and push these ideas, even at the risk of challenging and provoking other people in the organization (Janssen, 2003). Those with an innovative tendency emphasize the importance of unique, novel or original pathways (Isaksen, Lauer \& Wilson, 2003). In contrast, Miron-Spektor and colleagues (2011, p. 742) state that 'conformists are usually not the catalyst of radical ideas'. However, even smaller scale innovations are likely to challenge the existing framework of task relationships, informal norms, habits and expectations that coworkers have (Janssen, 2003). Bringing in new ideas to improve daily work processes and work designs also brings uncertainty, insecurity and stress. Often co-workers react with resistance rather than with support (Jones, 2001). Thus, individuals promoting original ideas must be willing to break habits and preferences for familiar practices, and risk a loss of cohesion, i.e. they are rule-breakers.

Hypothesis 2. Rule-breaking is positively associated with the generation of original ideas.

\section{Methods}

\section{Sample and Procedure}

Data has been collected online. The database for our study consists of alumni from a Business School $(N=707)$. Since intelligence is often considered as a necessary but not sufficient precondition of creativity (Sternberg \& O'Hara, 1999), we only contacted potential participants holding a university degree, assuming that they show a certain level of intelligence as well. As we were interested in the creative styles and performances of employees, we only contacted individuals currently employed. As it can be assumed that certain ranks, departments, firms and industries have certain demands concerning cognitive styles, we did not restrain sampling to one homogeneous group. Instead, we collected data in a variety of areas, aiming to cover the whole range of cognitive styles.

The final sample consisted of 191 individuals (response rate about 27\%), including 68 (about $36 \%$ ) women, with ages ranging from 22 to 65 years $(\mathrm{M}=32.47, \mathrm{SD}=7.31)$. To ensure commitment, we contacted each person personally via e-mail. The e-mail contained some general information about the purpose of the study, duration of the survey and contact information for potential questions. On the first page, participants were asked to carefully read the instructions on every page and to answer the questions thoroughly. They were further asked to avoid potential disturbances that may occur during the tests (e.g., by closing the door, muting their mobile phone). Besides these general instructions, we gave examples before continuing with the tests. For each test, the participants had 120 seconds to come up with as many original ideas as possible. After the time limit, the page was switched automatically to the next page. We also recorded the participants' cognitive style as the independent variable and socio-demographic variables as control variables.

\section{Measures}

\section{Originality and fluency}

To account for Kirton's note that individuals may solve problems in a particular way (instead of their preferred way if explicitly asked to do so) we do not, unlike other studies in the past (e.g., Isaksen \& Puccio, 1988), use different subtests for capturing performance in ideational fluency and originality (Torrance, 1974). Rather, we only use one test description, expecting that people with a preference for originality will solve the test differently from people with a preference for rule governance. Moreover, we expect that this diverging reaction to a stimulus holds in different creative tasks. Therefore, we chose to analyse two kinds of ideation tasks that the literature shows address important issues organizations may be confronted with. The first task is 'identifying unusual usage opportunities for an article of daily use', a task involving generating ideas away from the obvious or common (Torrance, 1974) and associating with organizational outcomes such as innovation, especially radical innovation. The second task is 'identifying similar expressions for a given term', a task involving generating ideas relating to existing knowledge and associating with organizational outcomes such as imitation or 
incremental innovation. In more detail, for the first measure of fluency and originality, we adapted a subtest of Torrance's Test of Creative Thinking (1974), asking the participants to mention as many unusual usage opportunities for a tin. This test has turned out to be suitable for measuring divergent productivity and allows analysis for ideational fluency and originality (e.g., Kim, 2006). For the second measure, we applied a creativity test by Schoppe (1975), which is labelled 'similarities' and allows the measurement of ideational fluency and originality as well by using rather convergent thinking. The participants were asked to come up with as many words that can be used to describe something 'nice'.

For both tests, we computed two measures; ideational fluency and originality, which - in line with other recent creativity studies such as De Dreu, Baas and Nijstad (2008) - serve as our study's dependent variables. For capturing ideational fluency, the number of unique ideas generated per participant was counted. To obtain a reliable measure of originality, two independent coders rated each unique idea for its originality, which - following De Dreu and colleagues (2008) - was defined as 'an idea or suggestion that is infrequent, novel and original' (from $1=$ not original to $5=$ very original). For both tasks, the unusual use task $\left(r_{\mathrm{wg}}=0.85\right.$, $\operatorname{ICC}(1)=0.70, \operatorname{ICC}(2)=0.82)$ and the similarity task $\left(r_{\mathrm{wg}}=0.89, \operatorname{ICC}(1)=0.66, \operatorname{ICC}(2)=0.80\right)$ inter-rater agreement was very high and hence satisfactory (LeBreton \& Senter, 2008). Differences between raters were solved by discussion. We use the value they agreed on for the following calculation of the average originality in a respondent's answers.

\section{Cognitive styles}

We measure the participants' cognitive styles with the well-established Kirton AdaptionInnovation Inventory (KAI, Kirton, 1976). KAI appears to be a reliable and valid tool for distinguishing innovative individuals from adaptive individuals along the three facets originality, efficiency and rule governance (Kirton, 2003). An increasing body of research has examined the different effects of the facets instead of the superordinate construct in order to gain a more detailed understanding of cognitive style (e.g., Miron et al., 2004) and given inconsistent (and in some studies, negative) correlations between facets (e.g., Loo \& Shiomi, 1997) and their differing consequences (e.g., Miron-Spektor et al., 2011). To measure originality, efficiency and rule governance, we applied the abridged 13-item version of KAI, which has been validated in numerous studies (Taylor, 1989a; Bagozzi \& Foxall, 1995). This version is most likely to avoid problems of multicollinearity when investigating the effects of the three facets on a dependent variable (Bagozzi \& Foxall, 1995).

Participants indicated on a seven-point response scale their agreement or disagreement with the statements attached to the items. The Cronbach's alphas in our sample for the three KAI dimensions, originality, rule governance and efficiency, were $0.83,0.64$ and 0.75 , which is in line with the expected values based on prior studies (see the literature overviews in Bagozzi \& Foxall, 1995 or Kirton, 2003). We used confirmatory factor analysis to further examine the reliability and validity of our measures. The three-factor structure yielded an acceptable fit $\quad(\mathrm{CFI}=0.91 ; \quad \mathrm{RMSEA}=0.08$; SRMR $=0.07$ ) and all item loadings were significant, indicating construct and discriminant validity. Moreover, the three-factor model produced a significantly better fit than a model in which the three dimensions were collapsed into one factor $(\mathrm{CFI}=0.56$; $\mathrm{RMSEA}=0.16$; SRMR $=0.14 ; p<0.001$ ), underlining our assumption of three distinct factors as opposed to one continuum. The relatively low or even negative correlations between the dimensions (see Table 1) are in line with results in other studies such as those of Miron and colleagues (2004) and give credence to our approach of analysing originality, efficiency and rule governance as distinct factors.

\section{Control variables}

Previous literature suggests that gender and age may be associated with creative style, creative performance, or both (Kirton, 2003). To control for potential confounding effects, we included these two variables in our analysis. Previous research also suggests that if a person produces a large number of alternatives, it is more likely that they also produce original ones (e.g., Dixon, 1979). We therefore control for fluency when examining originality by testing how far our hypothesized relationships change when controlling for fluency.

\section{Results}

Having ensured the applicability, reliability and validity of our data, we can move on to evaluating the hypotheses. Table 1 shows descriptive statistics for, and correlations among, the study's variables.

In order to test Hypothesis 1, we present two series of three hierarchical regressions, with the first series examining fluency in the unusual usage task and the second one examining fluency in the similarities task. Model 1a of Table 2 shows that the two control variables age and gender only explain $1 \%$ of variance in fluency 
Table 1. Means, Standard Deviations and Correlations among Variables

\begin{tabular}{lrrrrrrrrrr}
\hline & Mean & SD & $\mathbf{1}$ & $\mathbf{2}$ & $\mathbf{3}$ & $\mathbf{4}$ & $\mathbf{5}$ & $\mathbf{6}$ & $\mathbf{7}$ & $\mathbf{8}$ \\
\hline 1. Age & 32.47 & 7.31 & & & & & & & & \\
2. Gender $(1$ = female; 2 =male) & 1.64 & 0.48 & 0.08 & & & & & & & \\
3. Cognitive Style: Originality & 5.21 & 0.85 & 0.11 & -0.05 & & & & & & \\
4. Cognitive Style: Inefficiency & 2.83 & 0.90 & 0.04 & 0.07 & -0.33 & & & & & \\
5. Cognitive Style: Rule-breaking & 3.81 & 0.93 & 0.17 & -0.01 & 0.11 & 0.17 & & & & \\
6. Fluency (unusual usage) & 6.80 & 2.90 & -0.04 & -0.11 & 0.22 & -0.06 & 0.07 & & & \\
7. Originality (unusual usage) & 1.57 & 0.44 & 0.02 & 0.21 & 0.13 & 0.03 & 0.21 & 0.25 & & \\
8. Fluency (similarity) & 10.58 & 3.90 & 0.01 & -0.08 & 0.16 & -0.04 & 0.08 & 0.36 & 0.10 & \\
9. Originality (similarity) & 1.56 & 0.36 & 0.22 & 0.01 & 0.12 & 0.02 & 0.26 & 0.08 & 0.24 & 0.08 \\
& & & & & & & & & & \\
\end{tabular}

Note. $\mathrm{N}=191$.

Correlations of $|0.15|$ and above are significant at a 0.05 level (two-tailed).

Correlations of $|0.19|$ and above are significant at a 0.01 level (two-tailed).

Correlations of $|0.24|$ and above are significant at a 0.001 level (two-tailed).

Table 2. Hierarchical Regression Analyses Predicting Fluency in Two Different Tasks

Fluency in the unusual usage task

Model 1a Model 1b Model 1c
Fluency in the similarity task

Model 2a Model 2b Model 2c

\begin{tabular}{lcccccc}
\hline Age & -0.03 & -0.05 & -0.06 & 0.02 & 0.00 & -0.01 \\
Gender & -0.11 & -0.10 & -0.10 & -0.08 & -0.07 & -0.07 \\
Originality & & $0.23^{* *}$ & $0.22^{* *}$ & & $0.16^{*}$ & $0.17^{*}$ \\
Inefficiency & & & 0.01 & & & 0.00 \\
Rule-breaking & & & 0.05 & & & 0.07 \\
F-statistic & 1.21 & $4.16^{* *}$ & $2.58^{*}$ & 0.64 & 2.05 & 1.36 \\
$R^{2}$ & 0.01 & 0.06 & 0.07 & 0.01 & 0.03 & 0.04 \\
Change in $R^{2}$ & & $0.05^{* *}$ & 0.00 & & $0.03^{*}$ & 0.00 \\
\hline
\end{tabular}

Note. $N=191$. Two-tailed tests were performed. Standardized regression coefficients are reported in the table.

Significance levels:

$* p<0.05$

$* * p<0.01$

$* * * p<0.001$

in the unusual usage task, with none of the variables exerting a significant effect on the dependent variable. In Model $1 b$, we added the cognitive style originality. As hypothesized, originality is significantly associated with fluency $(\beta=0.23, p<0.01)$. The inclusion of originality explained an additional $5 \%(p<0.01)$ of the variance in fluency $\left(R^{2}=0.06\right)$. As a robustness check, we added the other two cognitive styles in Model 1c. The effect of originality is almost unchanged $(\beta=0.22, p<0.01)$ and, as expected, neither inefficiency ( $\beta=0.01$, n.s.) nor rule-breaking ( $\beta=0.05$, n.s.) is significantly associated with the dependent variable. The variance explained is almost unchanged at $6 \%$. Giving even more credence to our Hypothesis
1, the results for the dependent variable fluency in the similarities task are strikingly comparable. As shown in Model 2a, the two control variables are non-significant and explain only 1\% of variance in the dependent variable. The inclusion of originality in Model $2 \mathrm{~b}$ explained an additional $3 \%(p<0.05)$ of the variance in fluency $\left(R^{2}=0.03\right)$, with originality significantly associating with fluency $(\beta=0.16, p<0.05)$. Adding inefficiency ( $\beta=0.00$, n.s.) and rulebreaking $(\beta=0.07$, n.s.) does not significantly affect the effect of originality $(\beta=0.17, p<0.05)$ and does not lead to a significant increase in $R^{2}$ of fluency in the similarity task. Taking both sets of analysis together, Hypothesis 1 is supported. 
Table 3. Hierarchical Regression Analyses Predicting Originality in Two Different Tasks

\begin{tabular}{|c|c|c|c|c|c|c|c|c|}
\hline & \multicolumn{4}{|c|}{$\begin{array}{l}\text { Originality in the unusual usage } \\
\text { task }\end{array}$} & \multicolumn{4}{|c|}{$\begin{array}{c}\text { Originality in the similarity } \\
\text { task }\end{array}$} \\
\hline & $\begin{array}{c}\text { Model } \\
3 a\end{array}$ & $\begin{array}{l}\text { Model } \\
3 b\end{array}$ & $\begin{array}{l}\text { Model } \\
\text { 3c }\end{array}$ & $\begin{array}{l}\text { Model } \\
3 \mathrm{~d}\end{array}$ & $\begin{array}{l}\text { Model } \\
4 a\end{array}$ & $\begin{array}{l}\text { Model } \\
\quad 4 \mathrm{~b}\end{array}$ & $\begin{array}{l}\text { Model } \\
4 \mathrm{c}\end{array}$ & $\begin{array}{l}\text { Model } \\
4 \mathrm{~d}\end{array}$ \\
\hline Age & 0.01 & -0.03 & -0.04 & -0.03 & $0.22^{* *}$ & $0.18^{*}$ & $0.17^{*}$ & $0.17^{*}$ \\
\hline Gender & $0.21^{* *}$ & $0.21^{* *}$ & $0.22^{*}$ & $0.24^{* * *}$ & -0.01 & -0.01 & -0.01 & 0.00 \\
\hline Originality & & & 0.13 & 0.07 & & & 0.08 & 0.07 \\
\hline Inefficiency & & & 0.03 & 0.02 & & & -0.00 & -0.00 \\
\hline Rule-breaking & & $0.22^{* *}$ & $0.20^{* *}$ & $0.19^{* *}$ & & $0.23^{* *}$ & $0.22^{* *}$ & $0.22^{* *}$ \\
\hline Fluency (unusual usage) & & & & $0.25^{* * *}$ & & & & \\
\hline Fluency (similarity) & & & & & & & & 0.05 \\
\hline F-statistic & $4.24^{*}$ & $6.13^{* * *}$ & $4.30^{* *}$ & $5.91^{* * *}$ & $4.71^{*}$ & $6.86^{* * *}$ & $4.34^{* * *}$ & $3.67^{* *}$ \\
\hline$R^{2}$ & 0.04 & 0.09 & 0.10 & 0.16 & 0.05 & 0.10 & 0.11 & 0.11 \\
\hline Change in $R^{2}$ & & $0.05^{* *}$ & 0.02 & $0.06^{* * *}$ & & $0.05^{* *}$ & 0.01 & 0.00 \\
\hline
\end{tabular}

Note. $N=191$. Two-tailed tests were performed. Standardized regression coefficients are reported in the table.

Significance levels:

$* p<0.05$

$* * p<0.01$

*** $p<0.001$

To test Hypothesis 2, the first series of hierarchical regressions applies originality in the unusual usage task as dependent variable and the second series has originality in the similarities task as dependent variable. As depicted in Model 3a in Table 3, the two control variables account for $5 \%$ of variance in the dependent variable, with gender $(\beta=0.21, p<0.01)$ having a significant association with originality in the unusual usage task. The inclusion of rulebreaking in Model $3 \mathrm{~b}$ is associated with a significant increase $(p<0.01)$ of $5 \%$ in the variance in the dependent variable $\left(R^{2}=0.09\right)$. As hypothesized, rule-breaking is positively linked with originality in the unusual usage task $(\beta=0.22$, $p<0.01$ ). In Model 3c, we added the creative style variables originality and inefficiency. Neither exert a significant effect on the dependent variable (originality: $\beta=0.13$, n.s.; inefficiency: $\beta=0.03$, n.s.), nor do they affect notably the rule-breaking-originality relationship $(\beta=0.20$, $p<0.01$ ), nor is the variance explained notably changed $\left(R^{2}=0.10\right)$. Model 3d functions as an additional robustness check and includes fluency as additional independent variable to explain originality. Even if fluency has a significant association with originality $(\beta=0.25$, $p<0.001)$ and comes with an increase in variance explained $\left(R^{2}=0.16\right)$, it does not alter the effects of interest significantly.

With respect to the alternative dependent variable, originality in the similarity task, we found that in our control variable model (Model 4a) only age is significantly associated with originality $(\beta=0.22, p<0.05)$. The two controls account for $5 \%$ of variance in the dependent variable. Again in line with Hypothesis 2, rulebreaking is significantly associated with originality in the similarity task $(\beta=0.23, p<0.01)$ and its inclusion leads to a significant change of $5 \%(p<0.01)$ in the variance explained $\left(R^{2}=0.10\right)$. Model $4 \mathrm{c}$ adds the effects of the cognitive styles originality and inefficiency. Again, the effect of rule-breaking is not strongly affected $(\beta=0.22, p<0.01)$. The cognitive style originality is not related to the generation of original ideas in the similarity task $(\beta=0.08, \mathrm{n}$. s.), as is inefficiency ( $\beta=-0.00$, n.s.). There is a non-significant increase in variance explained $\left(R^{2}=0.11\right)$. Model $4 \mathrm{~d}$ adds fluency as the independent variable. However, fluency does not significantly associate with originality $(\beta=0.05$, n.s.). It does not alter the effects of interest and does not change the variance explained in originality. Taking both series together, Hypothesis 2 is supported.

\section{Discussion and Implications}

Ideas are the raw material necessary for innovation. Eliciting ideas with innovation potential from their employees can serve as a strong competitive advantage for organizations. Prior research suggests a positive relationship between the number of ideas produced with 
their originality (e.g., Isaksen \& Puccio, 1988; Kim, 2006). Yet, little empirical research has been carried out so far to explain why this should be the case. We have suggested an alternative view, which states that the cognitive styles 'originality' and 'rule governance' differently affect fluency and originality in idea generation. Our results are strikingly consistent and support our theoretical reasoning. In both tasks, the cognitive style originality and no other cognitive style affected ideational fluency significantly. Likewise, only rule governance affected the originality of ideas generated in both tasks. This link was not affected by controlling for fluency as an additional independent variable. Thereby we give further credence to existing knowledge and add several new insights to the discussion on the effects of cognitive styles.

While Kirton - in his original works (e.g., 1976) - has asserted that there should be no correlation between preferences for idea production represented by innovation-adaptor differences in the cognitive styles and the actual capacity to produce ideas, we find strong differences between adaptors and innovators in the styles 'originality' and 'rule governance'. This is, however, not surprising given that Kirton (2003) himself contrasted the sufficiency (adaptor) type of originality and the proliferation (innovator) type of originality along their tendency to produce few or many ideas in his later work. He stated, accordingly, that the former type will prefer and tend to produce fewer ideas and the latter type will prefer and tend to produce many ideas (Kirton \& Pender, 1982; Kirton, 1994, 2003). Hence our work contradicts Kirton's (1976) initial premise that cognitive styles are not related to creative outcomes. Admittedly, the cognitive style 'efficiency' is associated neither with the production of many ideas nor with the production of original ideas. This finding replicates existing studies that did not find a link between efficiency and creative outcomes (e.g., Lowe \& Taylor, 1986; Isaksen \& Puccio, 1988). However, and in line with existing studies such as those by Isaksen and Puccio (1988) or Goldsmith and Matherly (1987), we found differences between adopters and innovators in how their cognitive styles are related to idea generation. Goldsmith and Matherly (1987) found that originality has the strongest association with creative outcomes in general. While our research supports that the cognitive style originality is the mean for creating many ideas, for creating original ideas the cognitive style rule-breaking seems to be crucial. Hence, our analysis reveals significant differences between the cognitive styles and their relationships to idea generation. Thereby we also extend Isaksen and Puccio (1988), who found both originality and rule-breaking related to both fluency and originality in ideation but only conducted a correlational analysis that might have masked existing differences when considering all cognitive styles simultaneously.

Drawing on more recent research of Miron-Spektor and colleagues (2011), who encouraged identifying the unique contributions of the different cognitive styles offered by Kirton, we empirically examined Kirton's (2003) assumption of preferred ways of problem-solving and idea generation by giving the participants an implicit choice between the two outcomes (multitude versus originality). Our results are strikingly clear. In line with our hypotheses, the style originality affects ideational fluency and the rule governance style affects originality of ideas generated. Importantly, differences in the originality style do not affect the production of original ideas and differences in the rule governance style do not affect the multitude of ideas (fluency).

Taken together, our study reveals that two of the three cognitive styles are related to idea generation outcomes and extends existing findings in regard to differentiation. Hence, the main conclusion to be drawn from our study is that the different cognitive styles of KAI provide very different results in idea generation tasks. Thus, our research indicates that different cognitive styles, i.e. originality and rulegovernance, are needed for generating either a multitude or original ideas.

With regard to our research question, a single person can complement both cognitive requirements of idea generation. However, this combination is rare. Only $8.4 \%$ of the individuals in our study scored highly (5 or above) on both originality and rule-breaking (see Miron-Spektor et al., 2011 for a similar result). More often people tend to have one preferred cognitive style that they will use. As the cognitive style does not say anything about the ability to perform in the other category, people might excel in both, generating many and original ideas. However, this cognitive switch must be triggered by the task description.

Therefore, our paper contributes in two important ways. First we deepen the understanding of the underlying constructs composing the KAI. Although Kirton's inventory has been used for almost 40 years as a single scale used to measure cognitive style as one dimension, or as three aligned sub-scores still representing one underlying higher-order factor (innovation vs. adaption), our results provide further confirmatory evidence of the structure of the three-factor model and more importantly, of 
the different effects on idea generation. These conclusions, taken in the context of the criticisms by Payne (1987) and the recent findings by Miron-Spektor and colleagues (2011), have implications for the future of the use of the KAI inventory. Importantly, the inventory should no longer be used as a single scale as people might have all possible combinations of scores in the three dimensions. Mediocre scores, however, do not necessarily measure mediocre creativity. For many people, middle scores might just be a conflation between the different dimensions. More attention should be paid to differences between the styles and not only to differences within the styles. Hence, people might score high on either originality or rule-breaking both of which can be a sign for a creative element - either for fluency or for originality.

Second, we give a cognitive explanation for the underlying cognitive mechanisms of idea generation. This understanding might further help guide the development of new techniques that produce more high quality ideas. Hence, not only from a theoretical but also from a practical point of view, our insights are helpful - particularly, when organizations strive for radical changes. Among a plenitude of ideas, particularly original ideas bear the potential for radical innovation. Hence to arrive at original ideas, organizations should rely on members that can be characterized by a rule-breaking style.

Yet, given a particular organizational setting, a successful innovation might either depend on its radical uniqueness or on its timely or specific improvement. Timely and/or specific improvements often do not depend on a single radical invention. Instead, they might be related to potential application markets that may not yet exist, to alternative technological development directions around specific problems, to manufacturing processes or to alternative business models (O'Connor \& McDermott, 2004). Whereas for original ideas the feasibility aspect should be ignored until an idea is selected, ideas that need to be implemented quickly and with a minimum of financial resources, the originality aspect should get less attention. Hence, depending on the needs of an organization, firms either need highly original ideas, that challenge the status quo, or rather develop alternative ideas that rely on existing products, services and solutions and hence can be implemented easily and in a timely fashion.

Whereas the organizational circumstances cannot be influenced by our findings, we can make suggestions about whom to ask in an organization and how to ask. More specifically, organizations should rely on members with a strong rule-breaking tendency to generate original ideas and on members with a natural tendency for the cognitive style originality for generating a multitude of ideas.

\section{Limitations and Future Research}

In our study, we focused on the generation of ideas. This is based on the two rationales that (1) only original ideas have the potential for breakthrough innovation and organizations prefer one breakthrough idea over a plenitude of mediocre ideas (Girotra, Terwiesch \& Ulrich, 2010), and (2) idea fluency may be necessary for a timely and/or specific improvements within an organization. This understanding is both practically and theoretically relevant as it helps understand how organizations gain competitive advantage. Nevertheless, future research is invited to compare our results regarding the generation of ideas with the complementary factor of usefulness of ideas as innovation processes include several additional steps, such as idea selection, idea combination, idea promotion and idea implementation (Caniëls, De Stobbeleir \& De Clippeleer, 2014). Besides the fact that adequately considering all these steps in one research project would exceed the limit of the explicable, each of the named process steps may include additional or alternative processes, along with a deviation from our cognitive perspective. The idea selection step, for example, involves social processes such as negotiations in which self-assertion may be more important than cognitive styles. We encourage future research to test these additional factors from a process perspective within groups.

Further, all of our participants hold a university degree, which limits the generalizability of our results to this group. As mentioned, we did so to ensure a comparable and certain level of intelligence as a minimum of intelligence is supposed to be a necessary precondition for creativity. Additionally, we assume that those individuals play important roles in organizations. Future research might include additional, or examine other, populations.

\section{References}

Amabile, T.M. (2000) Stimulate Creativity by Fueling Passion. In Locke, E. (ed.), Handbook of Principles of Organizational Behavior. Blackwell, Malden, pp. 331-41.

Bagozzi, R.P. and Foxall, G.R. (1995) Construct Validity and Generalizability of the Kirton Adaption-Innovation Inventory. European Journal of Personality, 9, 185-206.

Caniëls, M.C., De Stobbeleir, K. and De Clippeleer, I. (2014) The Antecedents of Creativity Revisited: A 
Process Perspective. Creativity and Innovation Management, 23, 96-110.

Davis, M.A. (2009) Understanding the Relationship between Mood and Creativity: A Meta-Analysis. Organizational Behavior and Human Decision Processes, 108, 25-38.

De Dreu, C.K.W., Baas, M. and Nijstad, B.A. (2008) Hedonic Tone and Activation Level in the Mood-Creativity Link: Toward a Dual Pathway to Creativity Model. Journal of Personality and Social Psychology, 94, 739-56.

Diehl, M. and Stroebe, W. (1987) Productivity Loss in Brainstorming Groups: Toward the Solution of a Riddle. Journal of Personality and Social Psychology, 531, 497-509.

Dixon, J. (1979) Quality Versus Quantity: The Need to Control for the Fluency Factor in Originality Scores from the Torrance Tests. Journal for the Education of the Gifted, 2, 70-9.

Gino, F., Argote, L., Miron-Spektor, E. and Todorova, G. (2010) First Get Your Feet Wet: When and Why Prior Experience Fosters Team Creativity. Organizational Behavior and Human Decision Processes, 11, 102-15.

Girotra, K., Terwiesch, C. and Ulrich, K.T. (2010) Idea Generation and the Quality of the Best Idea. Management Science, 56, 591-605.

Goldsmith, R.E. and Matherly, T.A. (1987) AdaptionInnovation and Creativity: A Replication and Extension. British Journal of Social Psychology, 26, 79-82.

Goncalo, J.A. and Staw, B.M. (2006) IndividualismCollectivism and Group Creativity. Organizational Behavior and Human Decision Processes, 100, 96-109.

Harrison, D.A., Price, K.H., Gavin, J.H. and Florey, A. T. (2002) Time, Teams, and Task Performance: Changing Effects of Surface- and Deep-Level Diversity on Group Functioning. Academy of Management Journal, 45, 1029-45.

Hayes, J. and Allinson, C.W. (1994) Cognitive Styles and Its Relevance for Management Practice. British Journal of Management, 5, 53-71.

Isaksen, S.G., Lauer, K.J. and Wilson, G.V. (2003) An Examination of the Relationship between Personality Type and Cognitive Style. Creativity Research Journal, 15, 343-54.

Isaksen, S.G. and Puccio, G.J. (1988) Adaption-Innovation and the Torrance Tests of Creative Thinking: The Level-Style Issue Revisited. Psychological Reports, 63, 659-70.

Janssen, O. (2003) Innovative Behaviour and Job Involvement at the Price of Conflict and Less Satisfactory Relations with Co-Workers. Journal of Occupational and Organizational Psychology, 76, 347-64.

Jones, G.R. (2001) Organizational Theory: Text and Cases. Addison-Wesley, New York.

Kaufmann, G. (2004) Two Kinds of Creativity - But Which Ones? Creativity and Innovation Management, 13, 154-65.
Kim, K.H. (2006) Is Creativity Unidimensional or Multidimensional? Analyses of the Torrance Tests of Creative Thinking. Creativity Research Journal, 18, 251-9.

Kirton, M.J. (1976) Adaptors and Innovators: A Description and Measure. Journal of Applied Psychology, 61, 622-9.

Kirton, M.J. (1987) Adaptors and Innovators: Cognitive Style and Personality. In Isaksen, S.G. (ed.), Frontiers in Creativity Research: Beyond the Basics. Bearly, Buffalo, NY, pp. 282-313.

Kirton, M.J. (1994) Adaptors and Innovators: Styles of Creativity and Problem Solving, 2nd edn. Routledge, New York.

Kirton, M.J. (1999) Kirton Adaption-Innovation Inventory Feedback Booklet. Occupational Research Centre, Berkhamsted.

Kirton, M.J. (2003) Adaption-Innovation: In the Context of Diversity and Change. Routledge, London.

Kirton, M.J. and Pender, S. (1982) The AdaptionInnovation Continuum, Occupational Type, and Course Selection. Psychological Reports, 51, 883-6.

LeBreton, J.M. and Senter, J.L. (2008) Answers to 20 Questions about Interrater Reliability and Interrater Agreement. Organizational Research Methods, 11, 815-52.

Loo, R. and Shiomi, K. (1997) A Cross-Cultural Examination of the Kirton Adaption-Innovation Inventory. Personality and Individual Differences, 22, 55-60.

Lowe, E.A. and Taylor, W.G.K. (1986) Creativity in Life Science Research. RED Management, 16, 45-61.

Merton, R.K. (1957) Social Theory and Social Structure. Free Press, Glencoe, IL.

Miron, E., Erez, M. and Naveh, E. (2004) Do Personal Characteristics and Cultural Values that Promote Innovation, Quality and Efficiency Compete or Complement Each Other? Journal of Organizational Behavior, 25, 175-99.

Miron-Spektor, E., Erez, M. and Naveh, E. (2011) The Effect of Conformist and Attentive-to-Detail Members on Team Innovation: Reconciling the Innovation Paradox. Academy of Management Journal, 54, 740-60.

Nijstad, B.A., Stroebe, W. and Lodewijkx, H.F.M. (2003) Production Blocking and Idea Generation: Does Blocking Interfere with Cognitive Processes? Journal of Experimental Social Psychology, 39, 531-48.

O'Connor, G.C. and McDermott, C.M. (2004) The Human Side of Radical Innovation. Journal of Engineering and Technology Management, 21, 11-30.

Paulus, P.B. and Nijstad, B.A. (2003) Group Creativity: Innovation Through Collaboration. Oxford University Press, New York.

Payne, R. (1987) Individual Differences and Performance amongst R\&D Personnel: Some Implications for Management Development. RED Management, 17, 153-61. 
Puccio, G. and Grivas, C. (2009) Examining the Relationship between Personality Traits and Creativity Styles. Creativity and Innovation Management, 18, 247-55.

Rogers, C.R. (1959) Towards a Theory of Creativity. In Anderson, H.H. (ed.), Creativity and its Cultivation. Harper, New York, pp. 69-82.

Schoppe, K.-J. (1975) V-K-T. Ein Verfahren zur Erfassung verbal-produktiver Kreativitäts-merkmale. Hogrefe, Göttingen.

Sternberg, R.J. and O'Hara, L.A. (1999) Creativity and Intelligence. In Sternberg, R.J. (ed.), Handbook of Creativity. Cambridge University Press, New York, pp. 251-72.

Taylor, W.G.K. (1989a) The Kirton AdaptionInnovation Inventory: Should the Subscales Be Orthogonal? Personality and Individual Differences, 10, 921-3.

Taylor, W.G.K. (1989b) The Kirton AdaptionInnovation Inventory: A Re-Examination of the Factor Structure. Journal of Organizational Behavior, 10, 297-307.

Taylor, A. and Greve, H.R. (2006) Superman or the Fantastic Four? Knowledge Combination and Experience in Innovative Teams. Academy of Management Journal, 49, 723-40.

Tierney, P., Farmer, S.M. and Graen, G.B. (1999) An Examination of Leadership and Employee Creativity: The Relevance of Traits and Relationships. Personnel Psychology, 52, 591-620.

Torrance, E.P. (1974) Torrance Tests of Creative Thinking: Norms-Technical Manual. Ginn, Lexington, MA.
Weber, M. (1970) In Gerth, H.H. and Mills, C.W. (eds.), From Max Weber: Essays in Sociologyed. and trans.. Thomas Press \& Kegan Paul, London, pp. $1-28$.

Zhou, J. and George, J.M. (2001) When Job Dissatisfaction Leads to Creativity: Encouraging the Expression of Voice. Academy of Management Journal, 44, 682-96.

Carina Lomberg (calom@dtu.dk) is Assistant Professor of Entrepreneurship at Technical University of Denmark DTU. Her research focuses on factors that enable or hinder individuals or teams to be creative and to work entrepreneurially, whether in new or established firms.

Tobias Kollmann (tobias.kollmann@icb. uni-due.de) is the chair of e-business and eentrepreneurship at the University of Duisburg-Essen, Germany. His research focuses on questions of business venturing and business development in the net economy.

Christoph Stöckmann (christoph. stoeckmann@icb.uni-due.de) is assistant professor at the University of DuisburgEssen, Germany. His research focuses on such subjects as (corporate) entrepreneurship, management of innovations, leadership and creativity. 